\title{
Plato AND THE CAVE ALLEGoRY AN INTERPRETATION BEGINNING WITH VERBS OF KNOWLEDGE
}

\author{
Claudio César CAlabrese \\ Universidad Panamericana (Mexico) \\ ccalabrese@up.edu.mx
}

\begin{abstract}
In this paper we study the organization of the allegory of the cavern through the investigation of knowledge verbs. First, we briefly follow the interpretations of the allegory of the cave that we consider most significant and our perspective: all are valid provided that each does not deny the others. At our core we analyze the verbs of knowledge: how they relate to each other and what structure of knowledge they establish. In the conclusion, we affirm that the verbs do not present a vision of being as "what is", but as "what is being"; this means, with respect to the allegory, that the relation between being and intelligibility means a pathway of mutual equalization, which the prisoner of the cave goes through; nevertheless, the attempt to reach a comprehensive intelligence of the being requires one more step: to integrate the phenomena to the comprehension of the real thing.

KEYWORDS: Plato, Republic, ancient epistemology, cave allegory, myth.
\end{abstract}

\section{Theoretical framework}

If all reflexion, as it is inferred in a paper, implies a theoretical framework, then we are obliged to explain it as we will work on an assiduously visited text, and we will do it from a double perspective: a) the mutual dependency language - reality in the allegory and the ways language shapes the world and b) explaining what we understand by "verbs of knowledge".

In the first case, we consider language as that which provides a precomprehension of the reality, also described by von Humboldt $(1836,107-112 ; 1998$, 81-84) as "the universal forms of intuition and the logical ordering of concepts"; 
this thesis mediated by Paul Ricoeur (1975) underlays in our work; in that sense we should take into count that in the story of the cave we find the moulding of representations and the way they base reciprocally with the capacity of thought: rationality is sustained by a determined linguistic structure and vice versa. Such consideration applied to the reading of Plato demands for a certain distance away from the "cartesian habit" of thinking that language works solely as an intermediary between the world and the subject. It is in this framework that the verbs of knowledge would manifest pre-linguistic comprehension structures regarding the world, both in acknowledgement of this world and of these structures, as well as of its communication in the allegory: knowing through a phenomenal way is, by its own nature, always in progress and related to a comprehension of an intersubjective character. However, the Platonic setting also tries to indirectly make us aware of the nullity of the not-being, because we only get to know when we understand the appearance isn't any different from the being but from its "apparent being" (Ricoeur 1975, 11).

In the second point, we refer to those verbs that indicate intellectual activity and that additionally express an acquisition of knowledge. This takes us to set, alongside Ricoeur $(1975,310-314)$, the three tensions that we should consider when a metaphorical truth (vérité métaphorique) expresses a determined concept: a) the tension between the main and the secondary theme; b) the tension between a literal interpretation and a metaphorical interpretation that gives meaning to a story; $\mathrm{c}$ ) the tension in the relational or copulative function between the identity and the discrepancy that is wanted in a resemblance.

Regarding our investigation, we understand the previous points from this perspective: the language establishes the world's representation through concepts inside the judgement; for that reason, there isn't a world, nor thought without language, since it is the mediator between both (Humboldt 2003, 30).

We will take the following steps: a) justifying the comeback on a widely studied theme; b) considering the allegory inside the framework of Plato's thought; c) continuing to use the verbs of knowledge and their meaning in the framework of the cave allegory; d) conclusions.

\section{Why go back to the cave allegory?}

The attempt of presenting a reading of the cave allegory requires some justification, since it is a path travelled by avowed philosophers and researchers. While our research is not entirely new with regard to the literature on the topic, we consider that the perspective, that is, the follow-up on the verbs of knowledge, will bring contributions on the structure of the allegory and will allow comprehending Socrates' caution concerning the limits of his own interpretation, just as he 
presents it at 517 b: only a god would know if this is true. By considering this point, we move forward to a matter intimately linked to the former: in spite of Socrates declaring emphatically that the cave allegory refers to paideia and its absence among people ( $514 \mathrm{a}$ ), studies usually look in other directions, as presented before. The ambiguity of the analogy makes the question on its definitive meaning senseless, as it has no answer; each slope of the interpretation (gnoseological, political, religious, pedagogical) is true, on condition that they don't deny the remaining. Starting from this premise, we propose reading and interpreting the allegory from the perspective that paideia offers, that is to approach the experience of understanding human condition, that grows with the comprehension of the others.

Let's examine the essential of the input of each one of the aforementioned perspectives. In a political key, the story of the cave stops to reflect on the link between the philosopher and the order of the city (Abensour - Breaugh 2007, 955-982), explaining how the appearance of things and its underlying reality make intelligible the human, individual and social behaviours. From a religious point of view, the cave allegory is interpreted as a parable that adopts the Orphic initiation rites; the ascent of the cave implies liberation of the mind from the body's ties (Cornford 1941, 227; Hall 1980, 74-86). The gnoseological perspective (Killian 2012, 89-99; Zoyko 2008, 331-332), stresses the relationship between the line and the cave allegory and it takes us to two considerations; the first one coexists with the core of the post-cartesian philosophical tradition: to center itself on the epistemological problems and the bifurcation between senses and reason. If Socrates had centred the cave theme solely on the theory of knowledge, he would have never begun his story with a short but convincing invocation of paideia and its absence. It proves obvious to signal that the knowledge theme is present, but not as a "possibility condition", but as a transformation, that is to say the reading of the knowledge theme in a pedagogical key. By that we want to imply that there is in the story an identification between the subject who knows and his pursuit: the possibility of knowledge is reflected in the being of the one who knows; thus, the allegory represents both the beginning of the philosophical work and the calling of human knowledge. Indeed, paideia, in the complexity of its extents, is also a philosophical calling, the kind that is found beyond the natural desire of knowledge, since it brings in evidence the desire of knowing the being, the final meaning of the allegory. The darkness of the cave and its blurry images make apparent that the knowledge that doesn't lead to the being insufficiently represents the calling of the being. 


\section{Plato and the allegory}

Lewis (2013, 55-57; first edition 1936) sustains the impossibility of establishing an origin of the allegory in a strict meaning, the term of allegory is defined as a representation of the immaterial in a pictorial seat, since it is natural to the human language and thought. Obviously that representation doesn't only attend the narration of adventures, but, in its essential, it also attends a dramatic action. In that sense, a history of the allegoric exegesis should begin with Homer, as this kind of comprehension applies primarily to the epic poet. For the purposes of our article, we prioritize linking up the allegory concept with the semantic field of the "knowing", even though we demarcate the interdetermination horizon on which it holds on. In this context, "knowing" begins as "limiting something"; indeed, "defining" is one of the intelligibility elements and, thus, it proves meaningful to jot down that the "undefined" verbal forms emphasize the aspect where the verbal action is immersed: it isn't possible because there aren't any durative limits or, in Aristotle's vocabulary from his Physics (III, 6, 2007 a15), it lacks accomplishment.

In our case, establishing the limit of the interpretation implies registering the demarcation of the allegory. Off Ricoeur $(1975,31)$ we signal that limiting the interpretation means that it has been set on a concept or, more generically, it has been conceptualized; thus, distinguishing the comprehension of the interpretation signifies that the latter has the capacity to update the context of comprehension, making it (partially at least) inadequate. Because of it, we distinguish the classic allegory from the Christian one, as the latter fully concentrates on the writing and it has the following characteristics: "a one-to-one correspondence between each character and some concept, abstract principle, or element of the physical world" (Struck 2004, 3). We agree with the author on the fact that the allegory is, first of all, a reading phenomenon, based on the authority of the interpreted text. Even though it is a reading that regards the text as an expression of a profound cosmic structure, such literary critique lies upon two distinct, but complementary basis: on the one hand, the interpretation of existent texts and, on the other, the reference to the preceptive thought for the work not yet written. Certainly, it isn't about situating the allegory in the literary field as a singular perspective, as it is found immerse in the depth of the culture's life and it experiments changes and transformations that are proper to history (Lamberton 1986). With the secureness of the interpretation of a Neoplatonic stamp, especially with Macrobius (Setaioli 2004), the frontier between philosophy and literature begins to fade, guiding its exegetical endeavour to the mythical core, as it already appeared with clarity at Plato himself (Tim. 22 c-d; Phaed. 69 c; Wolfsdorf 2011, 5775). From this perspective, allegory implies for discovering a meaning that it is found beyond the literal, even though it casts roots in it; it is about a meaning 
that doesn't result immediately accessible to everyone. For that reason, allegory is what is established through the interpretation way as much as the interpretative process itself (Esparza 2017, 78-83). There are cautioned here two central aspects for our investigation: a) the demand to interpret the text in such manner that it would show the truthful content that it is a priori considered to be contained and b) the historic-cultural transformations ask for a permanent interpretation exercise, because its keys vary with said changes.

It is possible to understand the allegoric procedure on the symbolic horizon, since it preserves the bivalence between the significance and the significant, like two halves cut by a whole (Struck 2004, 92). The most archaic meaning for a symbol marks the beginning of its semantic evolution, which proves coincidental with technical expressions of the fortune telling. It is possible to strengthen this original link between the language of the auguries and the allegoric exegesis with the reference to the divinatory use of texts by Homer and Virgil and, in the Christian world, of the Bible. Therefore, the allegory is a symbol reduced to a sign, that is, the demarcation of one of its dynamic possibilities as a symbol (Calabrese 2018, 21-23). The sign is a semiotic expression, the conventional presentation of something already known: the allegory petrifies the symbol and it converts it into a sign, although it can keep its clothing. For M. Eliade (1987, 136-138), the symbol possesses a polyvalence of sense (actual aspects that the meaning per se takes), ordering its meanings in distinct plans of reality.

$$
\text { 3.1. The allegory ( } \varepsilon i x \omega \dot{\omega} v) \text { of the cave }
$$

We will present the development of the allegory as a whole to avoid its reduction to a singular theme, providing different observations on its scopes and meanings. In order for this approach to turn out productive, we should keep in mind, from the start, that Socrates describes the cave as an "image" ( $\varepsilon i x \omega$ ' $v$ ), and that it is found strictly linked to the story of the line, where he explained that the "conjecture" $\left(\varepsilon i x \alpha \sigma^{\prime} \alpha\right)$ is the least clear of the four apprehension faculties (509d; Grasso 2013, 525-541; Nehamans 2007, 3). The vagueness of a "blurry image" opens the space to our interpretation, keeping in count the etymological tie of each of these terms, starting with हैoเ $\alpha$ and then with घix $\alpha \zeta \omega$, which express the central idea of "representing through an image" (Chantraine 1977, 354-355; Hofmann 1943, 71). This lack of defined surroundings allows us to draw a tour; at first, it carries us to understanding that the beginning of the Republic contains, as if it could anticipate the allegories and, especially, the one of the cavern, an image that allows for a delimitation of the meaning that goes "underneath" the literal part:

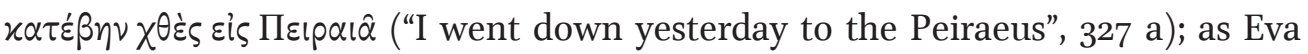
Brann observes (2011, 117-119), we can infer to a special meaning from the begin- 
ning of the work; she signals a linguistic aspect worthy to take in count: the

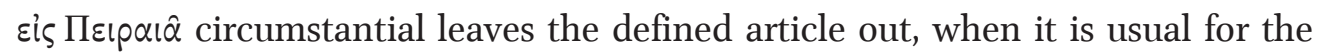
construction. As of now, the author understands that Plato seeks to recreate a subterraneous and hidden place and he reminds us that the feast to be celebrated that night and which draws Socrates' attention is in the honour of Bendis, Thrace goddess, warden of the entrance to the underworld and who is identified with Hecate. In this very sense, Socrates observes that Cephalus, his host and father of Polemarch, stands very aged, "on the threshold of old age" (528 2, quote of $\mathrm{I}, \mathrm{XXI}$, 6o); the beginning of the Republic, positions us then in the perspective of a katabasis or "descent", that, at first, seems befitting of the mysteries, but which, later, in the fullness of the story, it shows us the adventures of the philosopher and of philosophy. Indeed, Plato takes elements from the initiatory traditions with a philosophic meaning, to later retake the religious meaning with bigger depth (Ustinova 2009, 2-4). The notion of the world as a cave has a former meaning: in the Republic, the cave is the world of appearances (including the opinion), where we find the fettered ones or the ignorant ones, whilst the prisoner goes out to get to know the region that is "above" (Clay 1992, 113-129). Phaedo (109 a - 110 a) provides us with an antecedent, as Socrates presents the idea that we inhabit a small part around the sea, like ants or frogs alongside a pond, and that this happens in many places. "For I believe there are in all directions on the earth many hollows of very various forms and sizes, into which the water and mist and air have run together" (109 b); the earth per se is in the ether and its sediments flow towards the earth's hollows and this makes us believe we live on the surface. The cave, then, could as much be a small space where ignorant souls are incarcerated, or a spacious place where people of low comprehension live; in both cases, the cave is a place of confinement for the not illuminated, imprisoned by their ignorance and, thus, outsiders of the reality of the Good (Ustinova 2009, 4).

The setting presented by the cave is strictly linked to the senses' cognitive structure; the narrator-Socrates unfolds this consideration, without it implying that the ensemble of what exists be an object of the senses. The freed man (the text simply tells us that his fetters fall) represents the intuition over the sensible character of the being: his set-in motion expresses the human calling to reach the limits of the sensible (the cave). The tension expressed by the idea of "getting underway" is itself a search for intelligibility since it implies a desire to catch the entirety; it comes true in a second instance, together with the properly said output; we find there two of its dominating ideas: $\pi \alpha \iota \delta \varepsilon i \alpha$ and $\lambda \dot{\sigma} \sigma \varsigma$.

In W. Jaeger's words, which faithfully state the way the Greeks perceived themselves in the educational act, paideia participates in the life and growth of the society, as of an internal structuring that exists in its outset; indeed, the 
Greeks not only did they understand giving a start in time, but also arkhé, which is an origin or spiritual source (geistiger Ursprung): a place to return in search of an orientation (Jaeger 1973, 3-4).

The "liberation" ( $\lambda \dot{v} \sigma \varsigma)$ is the transition that a certain man initiates starting from the lack of paideia (the $\alpha \pi \alpha \iota \delta \varepsilon v \sigma i \alpha)$; according to Heidegger $(1976,217)$ this passage is marked by the way in which it is searched for a determined "shape", befitting for the paideia, which our author translates as Bildung, as long as we understand this term in its original meaning of "forming" or a process through which each one finds their own way to access the environment; we consider that showing intuitively the essence of paideia (original experience of the being) and the path to it is the former meaning of the simile. The first aspect puts us on guard - with a warning that keeps its topicality - against the idea that this process consists of a mere throwing of knowledge to the soul as if it was an empty container. On the contrary, in Heidegger's words (1976, 217), "Real education lays hold of the soul itself and transforms it (ergreif und verwandelt) in its entirety by first leading us to the place of our essential being (an seinen Wesensort) and accustoming us to it"(Thompson 2005, 157).

In this sense, the meaning of the cave allegory lays in the original unit of $\pi \alpha \iota \delta \varepsilon i \alpha$ and $\alpha \lambda \eta \dot{\theta} \theta \varepsilon ı$, second core of the dominant ideas of the text, according to Heidegger; the first one, as we have seen above, is fundamentally a "conversion", which means inhabiting whatever one comes upon (the splendour of what it is) and that "this displacement (Diese Versetzung) is possible only because everything that until then was accessible, and the mode (die Art) that as well was accessible, turns into another" (Heidegger 1976, 218). If, as we thought, the allegory of the cave is about this displacement from a region to another, that is, from the ways of the "dis-concealment" ( $\alpha \lambda \dot{\eta} \theta \varepsilon i \alpha)$ in each one of the homes, then we move forward to considering the core of our input: pursuing the verbs of knowledge in The Republic $514 \mathrm{a}-517 \mathrm{c}$ and as these arrange the story, in the distinct parts that we have considered and which we will develop later on.

\section{The organization of the passage beginning with the verbs of knowledge}

In the text of the allegory we distinguish at least three moments: in the first one, Socrates proposes a comparison on education and the lack of it, which bears an introductory value (514 a); next is the properly speaking development of the comparison ( $514 \mathrm{a}-517 \mathrm{a})$ and, in the third place $(517 \mathrm{a}-517 \mathrm{c})$, the explanation of the story given by Socrates $(517 \mathrm{a}-517 \mathrm{c})$.

We begin with the first part. The Greek text says: $\mu \varepsilon \tau \dot{\alpha} \tau \alpha \hat{v} \tau \alpha \delta \dot{\eta}, \varepsilon \hat{i} \pi \circ v, \dot{\alpha} \pi \varepsilon \dot{l}-$

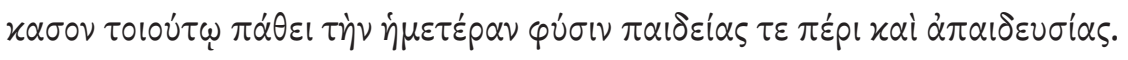


(Resp. 514 a: "Next - said I - compare our nature in respect of education and its lack to such an experience like this".)

The verb $\dot{\alpha} \pi \varepsilon i x \dot{\alpha} \zeta \omega$ establishes the general framework of an indirect exposition where Socrates proposes a certain similarity between the education processes of the soul and the liberation of the cave; while this verb is sustained by the general semantic of the verb "to represent", at the same time the latter is grouped in two fields: on the one side, it consolidates the meaning of "to represent" as the copy that one takes of a model; thus, in Aristotle's Poetic (1447 a) it is usually translated as "to imitate"; on the other side, the idea of "representing through the word", resorting to the imagination as one of its mechanisms (Cratylus 414 a). Thus, when pursuing a text from Phaedo (76 e), also linked to the representation, we preferred the translation "to compare". Even though it is not found in this passage, we remember the noun derived from this verb, $\alpha \pi \varepsilon i x \alpha \sigma i \alpha$, and its fundamental meaning of "image", "representation". Laws (668 c) offers one of the most significant texts, where we find this noun; Plato reflects here on the necessity for musicians and poets to compose according to correction and not to pleasure, in order to reach the best imitation. "And this is certainly true of music, as everyone would allow, -that all its productions are imitative and representative ( $\mu$ í $\mu$ -

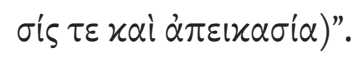

We consider this quote important, because Plato specifies mimesis' own action through the resource of image $(\dot{\alpha} \pi \varepsilon i \kappa \alpha \sigma i \alpha)$, which sustains the process of correct imitation. The verb $\dot{\alpha} \pi \varepsilon i x \dot{\alpha} \zeta \omega$ shows a representing way that carries a theoretical structure on which we wish to hinder; the expressive phenomenon supposed in this verb, which enables the pedagogical presentation from a metaphysical perspective, implies the theoretical problem of communication, since the expression way is the beginning of the ontological theory that Plato poses on the four degrees of knowledge; as such, it stands strictly linked to the distinction between sensible and intelligible aspects of the world which we find in book VI, through the image of the line and its subdivisions, to each one corresponding a level and an instrument of knowledge; the allegory that concerns us proves to be its explanation and, therefore, the pedagogical access for a conceptually dense thinking style. The correspondence between expression and interpretation expresses the primary comprehension that we present in these terms: the apprehension of an existing something is an absolute form of knowledge; it remains to add that this "absolute form" quickly proves inadequate, because, as Plato insists all along the Republic, knowledge, in order to be qualified as absolute, should have the characterization of an episteme; however, we consider that this allegory seems to imply that at the core of the comprehension we find a certain understanding, a certain logos (word and reason at the same time), although the problem of establishing if 
such knowing is objectively of the real stays open. If it is that way, in the aforementioned correspondence between expression and interpretation, Plato proposes the correspondence between distinct forms of being and various forms of knowing and that they are mutually ranked; we consider that the allegory's start up puts in evidence a crucial theme for Plato: if the formal regulation of thought implies the rationality of the real.

If we adjust the story to the previous reflexion, we center on that the object of the comparison is human nature in respect of education or lack of it with a determined experience $(\pi \dot{\alpha} \theta \circ \varsigma)$, which is what the allegory presents as "history". For it, Socrates requests to his interlocutor to think of men in some sort of cave

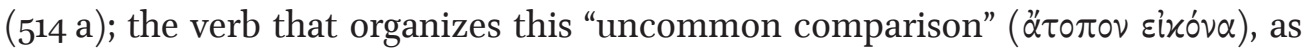
Glaucon will later express ( $515 \mathrm{a}$ ), is $i \delta \dot{\varepsilon}$; it carries the primary idea of "see", in its nearest physiologic meaning; the pleonasm "see with the eyes" is common at

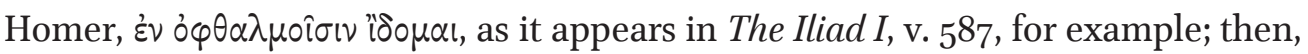
"to observe", "to examine", "to have an interview", in the meaning of "to have in sight"; and lastly, the figurative meaning of "to envisage", "to figure" (Bailly 1957, sv; Liddell 1996, sv). At this first level of signification we find the cave's essential scenography: men who have been fettered since childhood of such manner that they can't turn their heads around, above the light of a fire that shines behind them; later, a new effort to Glaucon's imagination (again the conjugated form $i \delta \dot{\varepsilon}$ ): there's a path between the fire and the prisoners, next to which a screen like the one puppeteers use. When the interlocutor states that he sees it ( $\dot{\rho} \hat{\omega} \hat{\omega}$, "all that I see", 515 b), Socrates asks that he also imagine ("op $\alpha$ qoivvv, "imagine also then", 515 b) men passing by carrying objects (the prisoners would only see shadows because of their position).

The following verbal form (olहı of o"opal) carries the ideas of "to think", "to believe", "to estimate" and it's at the center of Socrates' question, subsequent to the description: "Do you think that these men would have seen anything of themselves or of one another except the shadows...?" (515 a); Plato's teacher has transferred here the action of considering to the inside of the imagined: vopi $\xi_{\varepsilon l v}$ contains the exigency to reflect what those fettered men possibly "have seen" ( $\delta \rho \omega \varepsilon v)$, that is the projection of the shadows. And if there had been an echo, they would think (the verbal form o'ह anew) that the sound came from the shadows. Then,

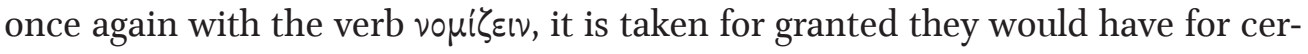
tain ( $\tau \dot{\partial} \dot{\alpha} \lambda \eta \theta \dot{\varepsilon} \varsigma$ ), that is for real, the world of the shadows they're perceiving.

A new stretch of the story begins when the liberation of one of the prisoners is considered; the conjugated form $\sigma x o ́ \pi \varepsilon$, present imperative of $\sigma \kappa \circ \pi \varepsilon \dot{\varepsilon} \omega$, invites Glaucon to "consider", to "estimate" the liberation of fetters ( $\lambda \dot{v} \sigma i \nu . . \tau \hat{\omega} \nu . . . \delta \varepsilon \sigma \mu \hat{\omega} \nu)$

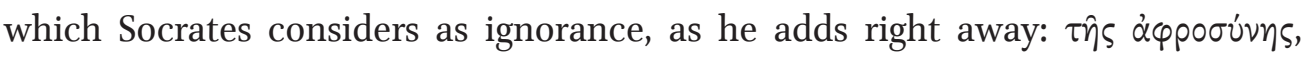


which also depends syntactically of $\lambda \dot{\sigma} \sigma v$; therefore the liberation is double: from the material fetters and from the ignorance that these imply; thus, this last expression, gets us ahead of the essential part of the allegory's meaning. It is important to point that Socrates signals the liberated had to be forced ( $\alpha v \alpha \gamma x \dot{\alpha} \zeta o$ i 0 ) to leave the cave and that once outside he would suffer and would feel hate for having been taken to light ( $516 \mathrm{a}$ ). It is possible to link this passage, on the one hand with Phaedo 82 e: we can collaborate with "our being prisoners", on account of the seduction of desire ( $(\dot{\varepsilon} \pi \theta u \mu(\alpha)$; and, on the other, with Meno 80 a-b (and this, at the same time, with Gorgias 510 b), when the interlocutor is irritated by the state of aporia ("you have reduced me to utter perplexity"), which coincides with the first phase of the Socratic method or acknowledgement of one's own ignorance. This allows us to better understand the beginning of the allegory; indeed, $\alpha \pi \alpha \_\delta \varepsilon v \sigma i \alpha$ ("the lack of paideia") proves to be more serious than the simple "lack of education", as it also signals absence of culture, in its wider sense, that is, a certain state of incivility.

After narrating the escape and the dazzle, the verbal form o"kı again: "What do you suppose would be his answer if someone told him ... that he is nearer to reali-

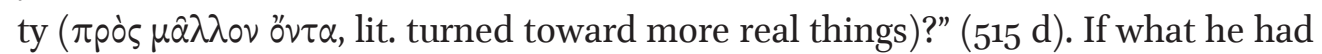
known were only shadows, what would happen from here on? The freed man will now need to get accustomed "to see things higher up" ( $\tau \dot{\alpha} \alpha \ddot{\nu} \nu \omega$ ő $\psi \varepsilon \sigma \theta \alpha \iota 516$ a); a second verb of vision (one composed from the previous one, $x \alpha \theta_{0} \rho \alpha \omega \omega$, "to see from higher up"), to indicate he would easier see the shadows, then objects reflected in the water and, lastly, the things themselves. A third vision verb is chained, $\theta \varepsilon \alpha \dot{\alpha} \mu_{\alpha l}$ (516 a), which takes us to intellectual reception ("to see examining", "to contemplate", "to consider", "to be a spectator at the theatre") of what is at his reach during the night in the sky; syntactically depending of the latter, $\pi \rho \circ \sigma \beta \lambda \dot{\varepsilon} \pi \omega \nu$, active present participle of $\pi \rho \circ \sigma \beta \lambda \dot{\varepsilon} \pi \omega$, which continues the aforementioned list of intellectual contemplation: "looking at the light of the stars and the moon". Then Socrates retakes the verbs of thought (oij $1 \mathrm{l}, 516 \mathrm{~b}$ ): he estimates the ways in which the freed man could directly perceive the sun; to continue with this semantic field, Plato's teacher later refers to what the newcomer would de-

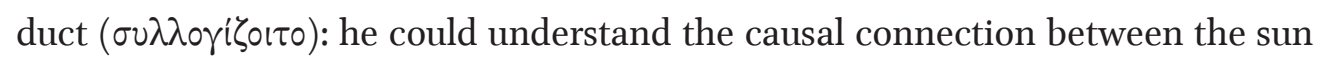
and the whole of what is seen. Once he has completed the adaptation process to the sunlight or to illumination, the freed man pities his former companions, the kind of deceitful wisdom to which they are habituated, and he decides to go back. In order to maintain the coherence of the story, the semantic route is inverted: his eyes would be dazed by darkness ( $\sigma$ xótos, $516 \mathrm{e}$ ). Even though he comes from directly contemplating the sun, he would be in disadvantage from those who remained fettered all this time; indeed, if he had to discriminate ( $\gamma \nu \omega \mu \alpha \tau \varepsilon v \dot{v} \nu \tau \tau \alpha{ }_{516}$ 
e) those shadows, he would appear again short of sight until his eyes would reset-

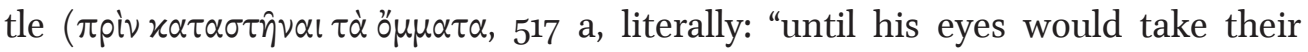
place"); during all this time, which would not be short - Socrates marks off - he would be exposed to ridicule, as his former companions would think that the decision to abandon the cave had deteriorated $(\delta 1 \alpha \varphi \theta \varepsilon i \rho \omega)$ his eyes; thus, Socrates concludes his story, they would kill him if they could lay hands on him (517 b; a clear reference to the iniquitous trial that condemned him to death).

Socrates' explanation to Glaucon follows: he must apply $\varepsilon i x \omega \nu v$ to the gnoseol-

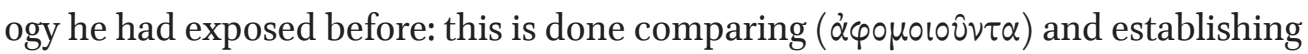
a series of connections that we will detail immediately. Before that we want to signal the importance of the participle of $\dot{\alpha} \varphi \circ \mu \circ \iota^{\prime} \omega$, as it anchors various degrees of comparison, that is, it determines the distinct meanings of "image" ( $\varepsilon \dot{i}(\dot{\omega} v)$;

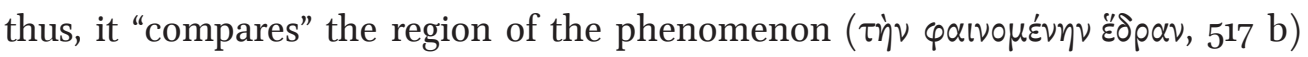

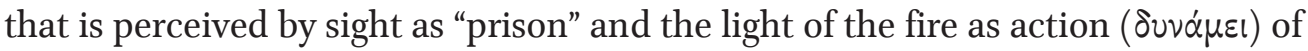
the sun; in the same way, he asks Glaucon to consider (517 b) the ascent as the journey of the soul to the intelligible ambit (

The correlation that Socrates has been presenting amidst the narration, the images and the concepts sustains the diversity of readings that we have considered; even though he puts a bridge between the phenomenon and its interpretation, it is clear that Socrates leaves other possibilities open or, at least, that he hasn't exhausted the interpretation in terms of truth.

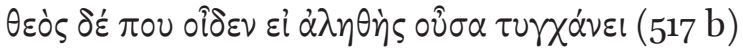

"... but God knows whether this is true at any rate".

With this limitation, Socrates develops an explanation of the allegory: in the limit of what is knowable through senses ( $\tau \dot{\alpha} \varphi \alpha \iota v o ́ \mu \varepsilon v \alpha, 517$ b) we find the idea of good and it is the cause of everything beautiful and right; it has generated light and its master in the visible ambit and truth and beauty in the intelligible ambit,

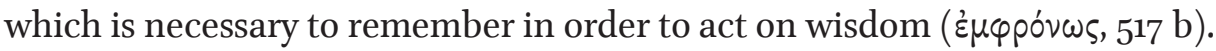

4.1 The organization of verbs of knowledge in the cave

The verbs of comprehension arrange the Platonic mechanism into three moments, which are intertwined in the story: a) the Socrates - Glaucon dialogue; b) liberation and escape of the prisoner from the cave; c) the enforcement of the story to the explanation of the real.

It is in this framework that $\dot{\alpha} \pi \varepsilon \mid x \dot{\alpha} \zeta \omega$ establishes the framework of the allegory, as Socrates establishes the following steps through this verb: "representing through the word" the difference between living a life with paideia and without it. Through the imperative form $i \delta \dot{\varepsilon}$, Socrates provides the script of the action: people who are fettered in a particular way since childhood, as they can only see in 
front of them, lit up by a fire that burns in a superior section, behind them; thus begins the movement of Glaucon's imagination towards comprehension; after his interlocutor says to have imagined according to request ( $\delta \rho \omega \hat{\omega}$, "all that I see", 515 b), Socrates poses a new demand to his imagination, ő $p$, that is, the effort for a second representation (the shadows that prisoners see). At this point, verbs are reiterated, as us, the readers, can "see" what Socrates asks Glaucon to imagine.

O'El, which is found in Socrates' new question ( 515 a), stimulates Socrates' interlocutor to consider what inhabitants of the cave think: now he has to establish

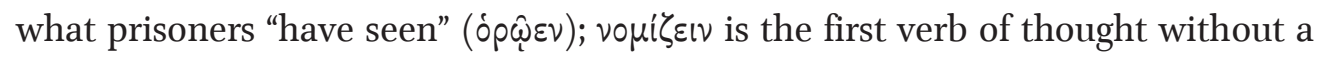
properly sensory root (Chantraine 1977, s.v. vóos; Hofmann 1949, s.v.) and it expresses with all certainty what prisoners would have as real. A third demand for Glaucon: "to estimate" ( $\sigma x o ́ \pi \varepsilon \iota)$ how liberation from material fetters and from ignorance would be; in this sense, three verbs that define the ascent of the now freed man depend of $\sigma x o ́ \pi \varepsilon l$ (516 a), $x \alpha \theta_{\circ} \rho \alpha \dot{\alpha} \omega$ and $\theta \varepsilon \alpha \dot{\alpha} \mu \alpha$ l (516 a). These are linked to the progress in knowledge: it is an invitation to look and see. The semantic fields propose a knowledge line through the establishment of a connection of thought with reality; the verbs quoted in the last sequence warn us that the being cannot be tried in his existence, that he can only be "seen", in the meaning set by its semantic. As a direct declaration on truth is not thus possible, one can only get to it through the labyrinthic structure of a cave.

\subsection{An interpretation beginning with verbs of knowledge}

Socrates proposes how we should understand the story (how to "put it in contact" or to "apply it" $\pi \rho \circ \sigma \alpha \pi \tau \varepsilon \dot{\varepsilon} \circ v, 517 \mathrm{~b}$ ); if in the text of the Republic we can understand the allegory as continuity of the Guardians' education, the link between $\pi \alpha \iota \delta \varepsilon i \alpha$ and $\dot{\alpha} \lambda \dot{\eta} \theta \varepsilon \iota \alpha$ introduces a metaphysical instance we should consider. As we have signalled, the subterraneous setting of the cave is dominated by a fire that illuminates defectively, by the shadows that produces its location and by all sort of utensils ( $\sigma x \varepsilon u ́ \eta, 514$ a; this noun designates in classic Greek all object made by man, Bailly 1957, sv). The ascent to the "upstairs" world is in correspondence with the ascent of the soul to the intelligible world; there the freed man perceives the

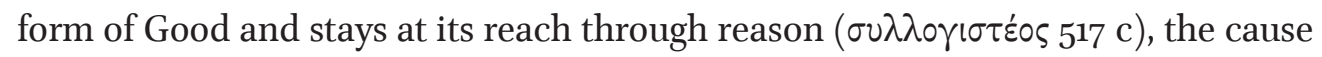
of all right and good. The work of the discursive reason, which is subsequent to the vision of Good, remembers the descending path from the line, involving a correlation between dialectics and the prisoner's climb after the natural objects. The soul's ascent makes Plato's idea of education visible and describes it as the

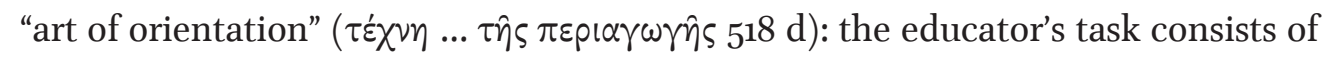
making souls turn, $\mu \varepsilon \tau \alpha \sigma \tau \rho \varepsilon \dot{\varphi} \omega, 518 \mathrm{~d}$. 
The turn toward things as they are and the light that shines upon them is one of the themes of the cave. The periagogé is not a simple conversion or intellectual movement; nor it is a mental reference to talk from the wall towards the light; but rather, periagogé is a complete turn of the body from the shadows towards the mouth of the cave. Our modern perspective, which sees through the lenses of a cartesian dualism, takes us to interpret that Plato processes what happens in the mind as something distinct of what happens in the body (Huard 2006, 13). This agrees with the most common practice of those educators for whom educating "is inserting sight into blind eyes" (518 b), since they consider that knowing doesn't exist in the soul ( $518 \mathrm{c}, 519 \mathrm{a}$ ), as if the power to learn wouldn't be in the organ that learns (Losin 1996, 52-53). Regarding "the art of orientation", as a turn of the shadows to light, irony takes a privileged place inasmuch as instrument that unfetters the knowledge process; it isn't present here as part of the art of the midwife, but according its most profound way of being: if irony is "saying one thing and meaning another", it also searches - like the allegory - a significance of the language behind the literal meaning (Vlastos 1991; Struck 2004: 45-50). It entails that if we accept that irony is distinctive of Plato's Socrates, then we are accepting as well that Plato adopted a style in which language levels can diverge; by it we signal a style of doing philosophy in which, actually, there had been considered a form of "allegoric" language or of an underlying meaning. At the same time, as Struck meticulously proves $(2004,41-50)$, Plato frequently makes reference in his dialogues to the allegoric and enigmatic language of other thinkers and writers; that is to say it is a way of reading and writing of which Plato is fully conscious.

This doesn't mean that our author has had an univocal position, even though he stayed true to the essential: if he considers the allegory as a pedagogically unsafe method in what concerns children ( $378 \mathrm{~d}$ ), Plato never denies its utility in the philosophical argumentation, that is to say his reasons to invalidate it are neither theological nor methodological; he centers his uneasiness on the difficulties of a subtle interpretation, not on the method itself. (Kennedy 2011, 6-7). The world of appearances is determined in the cave by our biological composition and by the cultural interpretation of things that our bodies experience; on this perspective there is a fact of maximum relevance: appearances are concealed and revealed. The concealment paradoxically reveals that the concealed is the "reality of things" (the allegory talks about what "is behind" the appearances). This distinction between appearances and reality is fundamental for the story of the cave, especially for the way in which it presents the inability of the cave's inhabitants to look backwards; this proves to be his most original assertion and, thus, most polemic. 


\section{Conclusion}

The interpretation of The Republic as a representation of the polis threatened by disintegration is, without a doubt, a common place; we won't use this expression as a synonym of something that has lost its meaning because of being repeated, but inasmuch as we consider it goes off high its intrinsic dynamic: the permanent conflict between man and state. In ideal terms, however, cosmos and politics stay bound from an ontological point of view. This is where the Platonic novelty lays, inasmuch as it only is possible to understand it "afterwards": what is ontologically and logically the first is known as the end of the process. In the cave allegory, we find it as a postulate: a god only knows if the contemplated in the story is true (517 b), that is that the first, a necessary condition, isn't available from the beginning in the investigation of the reality. Indeed, the prisoner that leaves the cave doesn't know what he will find, doesn't understand the reason of abandoning the safety of shadows; actually, it lacks knowledge concerning a brighter "beyond", that is to say that the prisoner feels, with all the weighing the term deserves, an absence that moves him (the philosopher Eros from the Symposium). It is obvious that by invoking "a god" Plato considers the absolute comprehension of Good as knowledge that surpasses the man's capacities, while they are relative to who knows: the first condition and the last aim aren't of historic nature, but divine. For this reason, the Good is a model: the divine world, which at Plato means intelligible, and the sensible world, the becoming of the opinion, aren't more than the human way of understanding reality, just as the dialectic unit of the story shows; the freed man who goes in search of the intelligible order, or those who stay fettered in darkness make reference to the condition of humanity. The liberation only competes the philosopher and, on account of received and interiorized education, he wishes to go back to the cave to free those who remain prisoners. These last ones represent the confinement of opinions, of oblivion of oneself, which really means "inability of judgement"; the rational capacity of the soul is, indeed, its immortality which, in the Platonic myths, rewards the "acting well", that is with rationality. On the contrary, remaining inside the limits of perceptions, of opinions, means living chained, to the point of wanting to kill he who tries to broadcast the existence of a bright place. Thus, we assert that the various interpretations of "the cave allegory" (gnoseological, political, religious, pedagogical) are true on condition of not considering them exclusive; yes, Socrates leaves a key to vertebrate an access point: how we live is the apex of wisdom.

As a consequence of the previously stated, we make a second observation. The meaning of the appearance-reality distinction rests on the ambiguity of showinghiding and on the way we understand these ambiguities as individuals and as a community. Thus, the question at core isn't permanently delimitating what ap- 
pearance is and what reality is, but understanding how humanity coexists with the perception of things as they appear and as they really are. If Plato states the distinction between appearances and reality, he doesn't do it, however, in a simple and direct way and the allegory of the cave teaches us why it is this way. The text presents the connection of things with the Idea, with all the difficulties this theory carries and of which Plato himself is fully conscious; however, in the cave allegory we don't find the theory the way it is usually presented. What is elusively said can be shown in many ways; at first, irony, that works by displacing the meanings in the wake of a certain effect. Later, remains the meaning that is left in the interpretation, that lives beyond what the author means; this method is particularly observed in the allegory of the cave, since, while Socrates gives us his meanings, the critique - as we have seen - has looked to what the text "really" says (what hasn't been said, but is considered present, according to Heidegger's precedent).

We consider Heidegger's interpretation has the undeniable value of putting at the center of the philosophical debate what is the truth and grants us an interpretation of the present in which we are: the truth is an opening process in which an essential moment is the non-truth: the steps of discovering the being call for understanding how is the being now; Heidegger's position rests on the acknowledgement of an initial form that holds the knowledge, even though the logical form resides in it: it is about the vision-idea, six $\omega$ v - Bildung, and the object ( $G e$ genstand), which is found in the opposite direction. Still pending the problem of the synthesis, of the connection of main elements of his debate (the problem of appearing, the relation between the particular and the constitution of the object), which is precisely the core of the problem of the form.

"To see that he knows", which we pursued in the verbal semantics, entails a principle of metaphysics: knowing the nature of reality is identical to understanding that each one of the things is identical in nature. Actually, the question that starts the philosophy is: what matter constitutes the reality? Behind the answers basted by the Pre-Socratics, it was clear that the being is the last element of reality. Plato's text confirms this last frontier.

What underlays the allegory is an essential truth, inherited by Parmenides: wherever we direct our glance on the reality we won't find a better discovering than its own existence; a second principle of Platonism becomes obvious here: if the being and the beings concur inwardly and with existing, it became imperative excluding from the current existence everything that doesn't exist in the being thus characterized; actually, the sensible world is determined by pluralism (each thing is identical to itself, but different to the others): there is no singularity in the cave, nor homogeneity or simplicity, but plurality, diversity, mutability. 
In this sense, the comprehension of the verbs of knowledge show that their semantic fields of vision/comprehension don't present a vision of the being as "what it is", but as "what it is being"; with regards to the allegory, this means that the equalization between being and intelligibility meant a path, the one travelled by the prisoner from the cave in his ascent: in order to make the being exhaustively intelligible it is needed to go beyond the being.

\section{REFERENCES}

Abensour, Miguel \& Breaugh, Martin (2007) "Against the Sovereignty of Philosophy over Politics: Arendt's Reading of Plato's Cave Allegory," Social Research 74.4, 955-982.

Brann, Eva (2011) The Music of the Republic. Essay on Socrates' Conversations and Plato's Writings. Philadelphia: Paul Dry Books.

Calabrese, Claudio C. (2018) "Alegoría, mito y artes liberales en san Agustín, De ordine I. 8. 24," Graeco-Latina Brunensia 23.1, 21-34.

Chantraine, Pierre (1977) Dictionnaire étymologique de la langue grecque: histoire des mots. Paris: Klincksieck.

Clay, Diskin (1992) "Plato's first words," in: F. Dunn \& T. Cole, eds. Beginnings in Classical Literature. Cambridge University Press, 113-129.

Cornford, Francis M. (1941) The Republic of Plato. New York / London: Oxford University Press.

Eliade, Mircea (1987) The Sacred and the Profane. The nature of the religion. New York / London: Harcourt.

Grasso, Elsa (2013) "Images dans le texte: l'eikonologia platonicienne," Revue de Métaphysique et de Morale 4, 525-541.

Esparza, Gustavo (2017) "La física simbolista y la literatura fantástica: una entreveración metodológica para la interpretación de 'Las fuerzas extrañas'," Revista de Letras 57.1, 71-86.

Heidegger, Martin (1976) “Platons Lehere von der Wahrheit," Wegmarken (Gesamtausgabe, Band 9, Frankfurt am Main: Vittorio Klostermann) 203-238.

Hofmann, Johann Baptist (1949) Etymologisches Wörterbuch des Griechischen. München: Verlag von R. Oldenburg.

Huard, Roger L. (2006) Plato's Political Philosophy: The Cave. Washington DC: Algora Publishing.

Humboldt, Wilhelm von $(1836$; 2003) Über die Verschiedenheit des menschlichen Sprachbaues und ihren auf die geistige Entwicklung des Menschengeschlechts. Weisbaden: Fourier Verlag.

Humboldt, Wilhelm von (1999) On language. The diversity of human language structure and its influence in the mental development of the mankind. Cambridge / New York, Cambridge University Press.

Jaeger, Werner (1973) PAIDEIA. Die Formung des griechischen Menschen. Berlin / New York: Walter de Gruyter.

Kennedy, J. B. (2011) The Musical Structure of Plato's Dialogue. New York: Routledge. 
Killian, Jeremy (2012) "That Deceptive Line: Plato, Linear Perspective, Visual Perception, and Tragedy," The Journal of Aesthetic Education 46.2, 89-99.

Lamberton, Robert (1986) Homer the theologian: Neoplatonist allegorical reading and the growth of the epic tradition. Berkeley / Los Angeles / London: University of California Press.

Lewis, Clive Staples (2013) The Allegory of Love. A Study in Medieval Tradition. New York: Cambridge University Press.

Liddell, Henry George R.; Robert Scott (1996) A Greek-English Lexicon, gth ed. Oxford: Oxford University Press.

Losin, Peter (1996) "Education and Plato's Parable of the Cave," The Journal of Education $178.3,49-65$.

Nehamans, Alexander (2007) "Only in the contemplation of Beauty is human Life Worth Living, Plato, Symposium 211 d," European Journal of Philosophy 15.1, 1-18.

Ricoeur, Paul (1975) La Métaphore Vive. Paris : Éditions du Seuil.

Setaioli, Aldo (2004) "Interpretazioni stoiche ed epicuree in Servio e la tradizione dell'esegesi filosofica del mito e dei poeti a Roma (Comuto, Seneca, Filodemo)," International Journal of the Classical Tradition 11.1, 3-46.

Struck, Peter T. (2004) Birth of the Symbol. Ancient Readers at the Limits of Their Texts. Princeton, NJ / Oxford: Princeton University Press.

Thompson, Iain D. (2005) Heidegger on Ontotheology: Technology and the Politics of Education. Cambridge: Cambridge University Press.

Ustinova, Yulia (2009) Caves and the Ancient Greek Mind:Descending Underground in the Search for Ultimate Truth. Oxford: Oxford University Press.

Wolfsdorf, David (2011) "Plato's Conception of Knowledge," The Classical World 105.1, 5775 .

Zovko, Marie Élise (2008) "The Way Up and the Way Back is the Same. The Ascent of Cognition in Plato's Analogies of the Sun, the Line and the Cave and the Path Intelligence Takes", in: John Dillon and Marie Élise Zovko, eds. Platonism and Forms of Intelligence. Berlin: Akademie Verlag, 313-341. 